\title{
Simulation of Rectangular Ring Micro-Strip Patch Antenna to Enhance Impedance Bandwidth for UWB Wireless Applications
}

\author{
Anant Raj Mishra ${ }^{\mathrm{a}}$, Ankit Gambhir ${ }^{b^{*}}$, Rajeev Arya ${ }^{\mathrm{c}}$ \\ ${ }^{a}$ Galgotias University, Greater Noida UP 201310,India \\ ${ }^{b}$ Delhi Technical Campus(GGSIPU), Greater Noida UP 201306, India \\ ${ }^{c}$ CMR Engineering College (JNTU), Hyderabad Telangana 500085 India
}

Received: 07 April 2017; Accepted: 06 August 2017; Published: 08 January 2018

\begin{abstract}
In this paper, simulation of rectangular ring micro-strip patch antenna for ultra wideband (UWB) wireless applications is done. The attractiveness of this antenna is that it employs solo patch that makes it easy to fabricate and economical as well. It also mitigates the issue of misalignment. By making use of matching rectangular strips, impedance bandwidth enhancement is also attained. At centre frequency return loss is not more than $-10 \mathrm{~dB}$. It demonstrates superior radiation characteristics and reasonable gain in the whole operating band. In the designing of proposed antenna, micro-strip feeding is used for power supply purpose. CST Microwave studio suit 10 is used for the simulation purpose of the proposed antenna, which is a 3D electromagnetic field tool for simulation of electromagnetic field in all frequency bands. After simulation of proposed antenna, enhancement in impedance bandwidth of $20.60 \%$, frequency range of $1.8533 \mathrm{GHz}$, radiation efficiency of $92.51 \%$, and gain of $3.765 \mathrm{dbi}$ are obtained.
\end{abstract}

Index Terms: Ultra Wideband (UWB), Ring Micro-strip Patch Antenna, Impedance Bandwidth, Radiation Efficiency, Gain.

(C) 2018 Published by MECS Publisher. Selection and/or peer review under responsibility of the Research Association of Modern Education and Computer Science

\section{Introduction}

After studying the different materials, it has found that dielectric resonators are efficient radiator and energy storing element [4]. It is easy to design dielectric resonator antenna (DRA); because of its features such as small size, high radiation efficiency and simple structure [4] moreover it provides wideband width and low

* Corresponding author. Tel:

*E-mail address:er.ankit.gambhir@gmail.com 
Conductor loss. After examination of different dielectric resonator shape, it is found that some shape gives better impedance bandwidth.

For excitation of antennae we can use different feeding method. Such as micro-strip feeding, disk feeding, slot line feeding, coaxial feeding etc. we have used coaxial feeding as this provides better matching [4]. As mentioned objective of this paper is to simulate rectangular ring micro-strip patch antenna to enhance the impedance bandwidth, to minimize return loss, to increase the input impedance and more over to generate a radiation pattern in which there is minimum back radiation for UWB wireless application. To enhance the impedance bandwidth to its maximum extent rectangular ring patch is used. For feeding purpose micro-strip feeding concept is used. This type of design gives maximum gain relative to isotropic antenna. From some previous researches, it has found that rectangular ring micro-strip patch gives more impedance bandwidth than normal patch antenna.For superior antenna performance, a thick dielectric substrate with low dielectric constant is advantageous as this provide large bandwidths, high radiation power and better efficiency concurrently reduce conductor loss and $\mathrm{Q}$ factor. For antenna designers, bandwidth enhancement is main concern. Enhancement of bandwidth can be achieve by working on different parameter such as by varying probe height, or thickness of dielectric substrate, or by changing of dielectric constant of substrate, etc. If we compare dielectric resonator antenna with other antenna such as micro-strip antenna, we will find out that dielectric resonator antenna (DRA) has better antenna efficiency and wider bandwidth.

\section{Related Work}

A dual-band antenna can replace two single band antennas work for two frequency bands. The work on wideband stacked DRA was an implication to the design of dual-band DRAs by choosing two DRAs of having different dimensions but they are excited by a single feed. A wide band antenna has no use if it is not operating over a useful application band. This suggests the design of independent application bands where the antenna radiates only over the useful bands. Z. Fan et al. introduced a slot excited double element rectangular DRA for dual or wideband application. Three-band behaviorof antenna was found when two cylindrical DRAs were stacked and excited by annular ring. In dual frequency operation was achieved by incorporating an additional DRA in to a parent DRA where both DRAs are cylindrical in shape, so that the volume of the structure remains unchanged. Dual resonance is achieved by feeding a cylindrical ring DRA by using two orthogonal micro-strip feed lines. This also has the effect of producing orthogonally polarized bands but with similar broadside radiation patterns. Special eye-shaped DRA is also shown to be effective in producing dualradiating modes. Dual-frequency operation can also be achieved by embedding an additional radiator to the DRA. This principle is implemented in where a cylindrical DRA and a ring slot are fed together by a circular slot thereby allowing radiation from the two at respective resonances. it will be advantageous in this context if the feed to the DRA is also radiating at a particular frequency. This technique is explained in where the rectangular slot-feed to the DRA is made to radiate at a particular frequency by adjusting its dimensions. The same team introduced another design by using a T-shaped micro-strip feed that radiates in addition to exciting the DRA. A ceramic loaded annular ring monopole antenna is found to resonate in the dual W-LAN bands.

\section{Antenna-Structure}

\section{i. $\quad$ Micro strip feed line placement}

As shown in figure 1, micro-strip is placed on the top of substrate so that it's one end can touch the rectangular ring patch, dimensions are chosen as length $l=6 \mathrm{~mm}$ (xfrom $+4 \mathrm{to}+10)$, width $w=3.59 \mathrm{~mm}$ (y from1.795 to +1.795$)$ and thickness $t=0.25 \mathrm{~mm}(\mathrm{z}$ from +3 to +3.25$)$. 

for UWB Wireless Applications

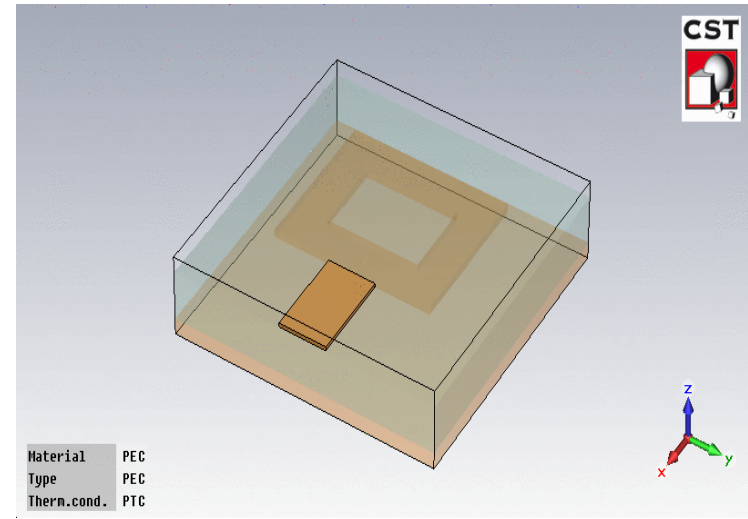

Fig.1. Micro-strip feeding

ii. $\quad$ Selection of port for power supply

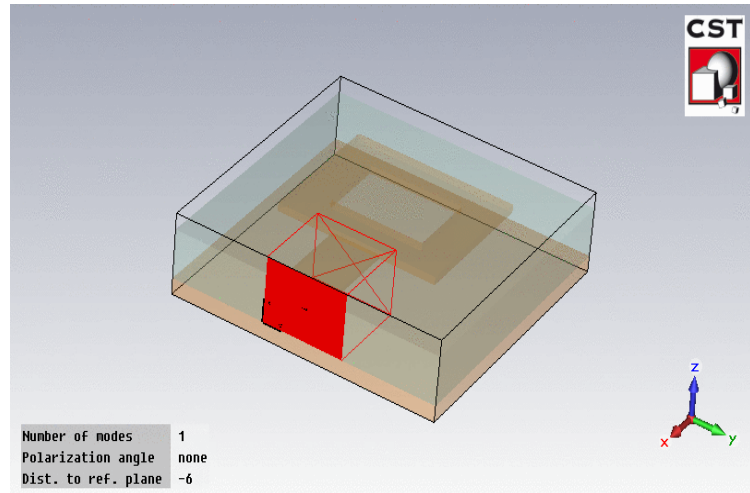

Fig.2. Selection of port for power supply

iii. $\quad$ Finishing structure of proposed antenna with port.

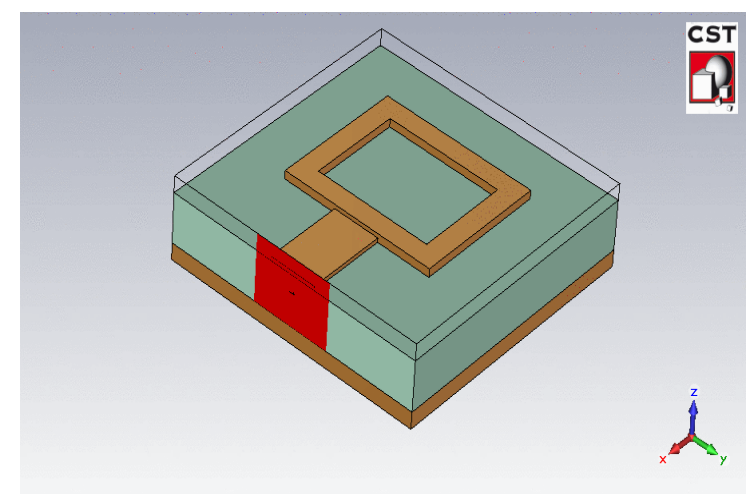

Fig.3. Final structure of proposed antenna 


\section{Simulated Results}

\section{i. $S$ - Parameter}

The structure has been simulated and S-Parameter is shown in Fig.4, it is found that resonant frequency is 9 GHz with bandwidth $1.85 \mathrm{GHz}$ ranging from 3 to $12 \mathrm{GHz}$ (where $\mathrm{S}_{11}<-10 \mathrm{~dB}$ ). Maximum return loss is up to $-24.126 \mathrm{~dB}$ at the resonant frequency. The return loss, $S_{11}(\mathrm{~dB})$ is shown in Fig. 4, where we can clearly see the maximum dip is at $9 \mathrm{GHz}$.

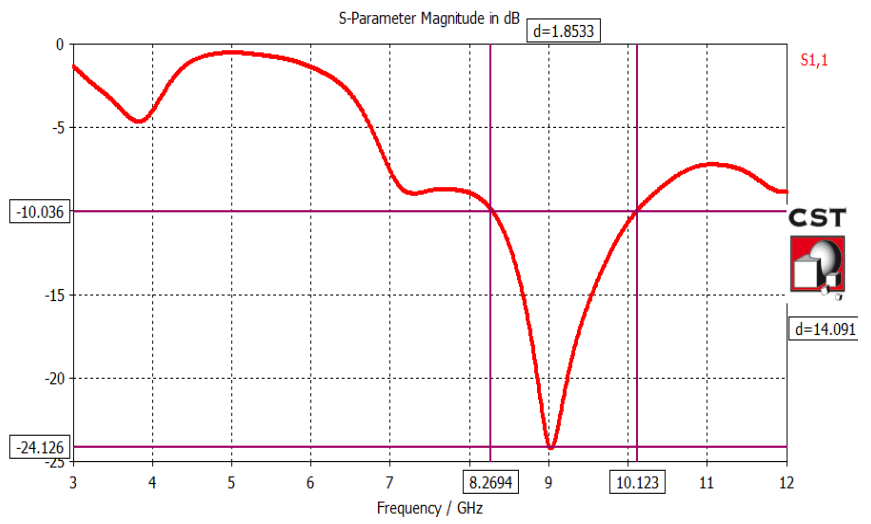

Fig.4. S-parameter, S11 in dB

\section{ii. Farfield Radiation Pattern and its 3D Plot}

At resonant frequency of $9 \mathrm{GHz}$, Farfield radiation pattern is shown in Fig. 5, which shows maximum gain of antenna, is 3.765dBi. A polar plot of Gain Theta and Gain Phi, in Fig. (a), Fig.(b) respectively is also shown to understand the variation with change in Theta and Phi. For Gain Theta plot, its main lobe direction is $90 \mathrm{deg}$. and its magnitude is $3.4 \mathrm{~dB}$. For Gain Phi Plot, main lobe direction is $0 \mathrm{deg}$. and its magnitude is $-11.4 \mathrm{~dB}$.

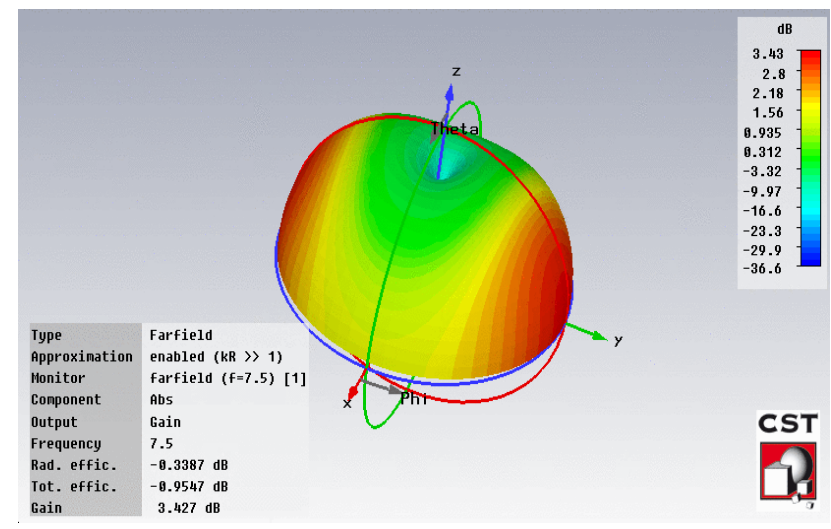

Fig.5. Gain 


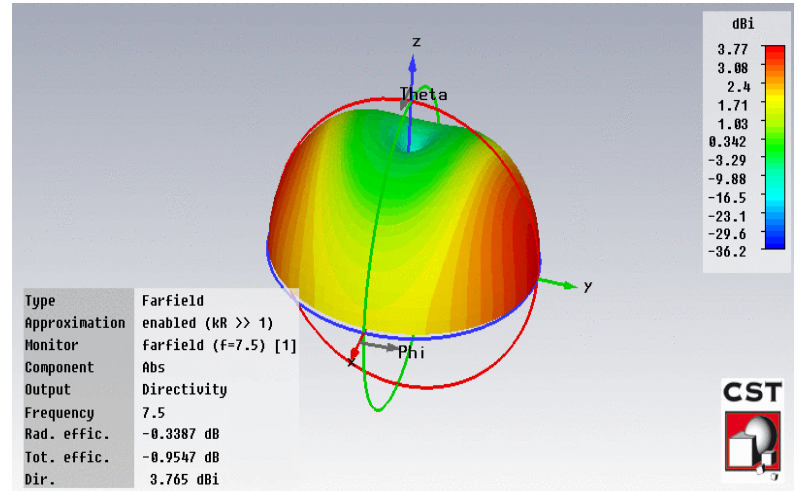

Fig.6. Directivity

As from the Fig. 5 and Fig .6 gain and directivity are $3.765 \mathrm{dBi}$ and $3.427 \mathrm{~dB}$ respectively. Total radiation efficiency can be calculated as:

$$
\begin{gathered}
\mathrm{R}_{\mathrm{eff}=}(3.427-3.765) \\
\mathrm{R}_{\mathrm{eff}}=-0.338 \\
\mathrm{R}_{\mathrm{eff}}=10^{(-0.338 / 10)} \\
\mathrm{R}_{\mathrm{eff}}=(0.9251 * 100)=92.51 \%
\end{gathered}
$$

The above calculation shows that the proposed antenna is $92.51 \%$ efficient.

\section{iii. E-Field and H-Field Distribution Pattern}

Field distribution pattern E-field distribution and H-field distribution are shown below in Fig. 7 and Fig. 8, these plots are found at resonant frequency $9 \mathrm{GHz}$.

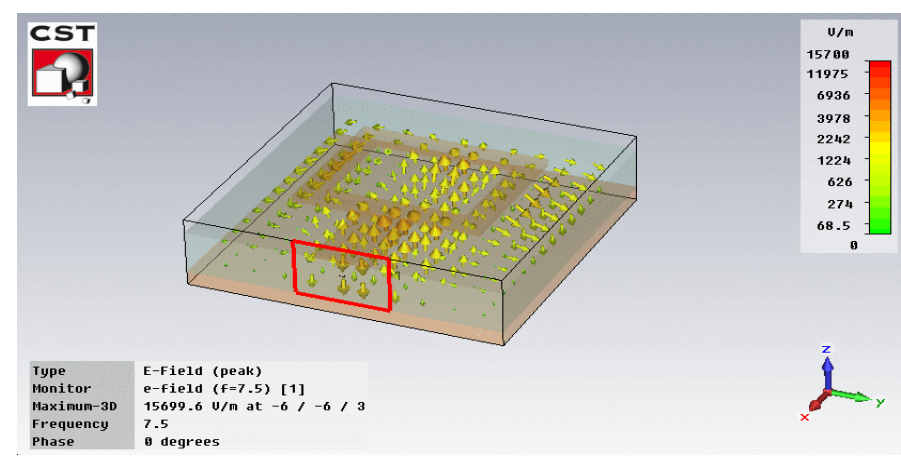

Fig.7. E-field distribution 


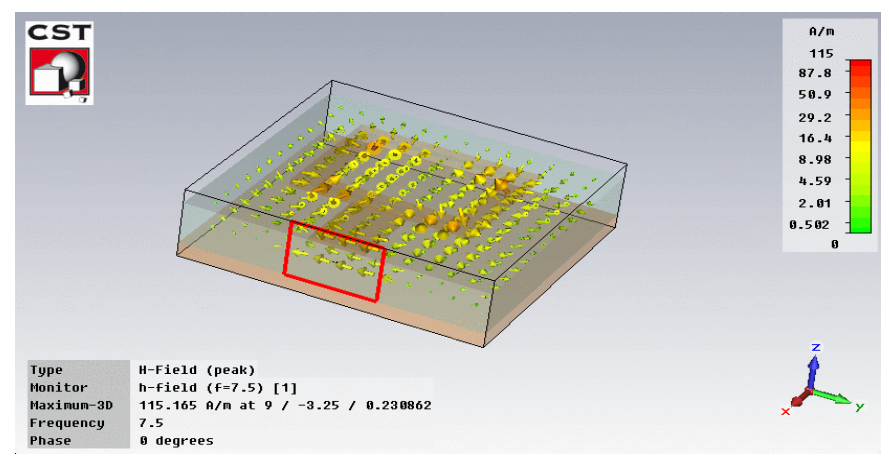

Fig.8. H-field distributions

\section{iv. VSWR Plot}

Voltage standing wave ratio (VSWR) is used to measure to find out how perfectly antenna is matched with transmission line. The simulated VSWR of proposed antenna is shown in Fig. 9. The matching frequency range is from 3 to $12 \mathrm{GHz}$, where the VSWR $<2$ and return loss $\left(\mathrm{S}_{11}\right)<-10 \mathrm{~dB}$.

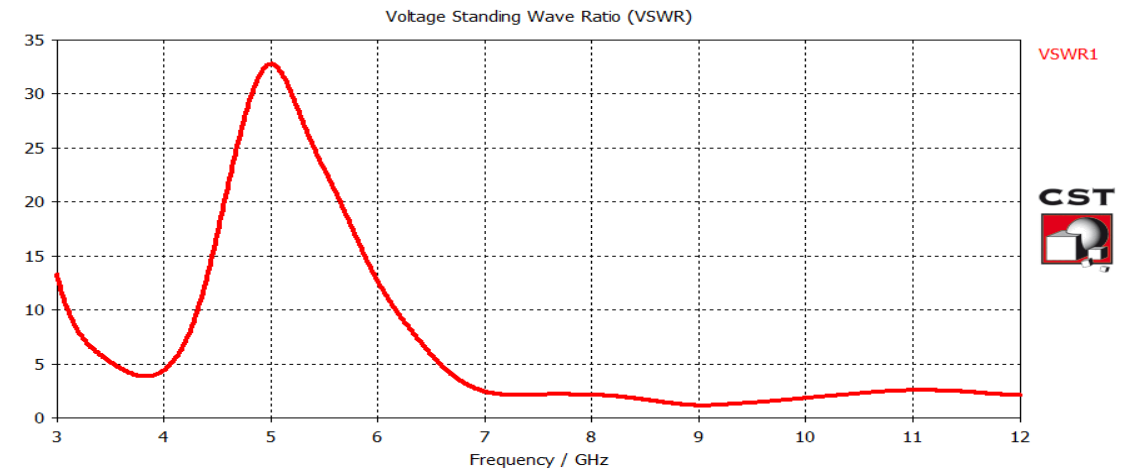

Fig.9.VSWR for proposed antenna

\section{Conclusions \& Future Scope}

Simulation results of rectangular ring micro-strip patch antenna to enhance impedance bandwidth for UWB wireless application is presented and examined numerically using CST microwave studio suit 10. By varying height of probe, a wideband antenna is simulated with the following specifications. Bandwidth of $1.8533 \mathrm{GHz}$ ranging from $8.2694 \mathrm{GHz}-10.123 \mathrm{GHz}$, where return loss is not more than $-10 \mathrm{db}$ at resonant frequency $(<-10$ $\mathrm{db} \mathrm{S}_{11}$ ), enhancement of impedance bandwidth $20.60 \%$, radiation efficiency of $92.51 \%$, total efficiency of $80.27 \%$ and gain of $3.765 \mathrm{dbi}$. Future work could be stretched out by considering usage of streamlining systems on the other hand the DRA; some scientific models are obliged to get an acceptable thought of aspects of antenna. Great fabrication techniques ought to be emulated to minimize the measured errors. Based on the antenna design, following points are found which would be considered helpful for future investigations. The impedance bandwidth of the rectangular ring micro-strip patch antenna can be enhanced by using multiple rectangular ring micro-strip patch antennas in array pattern. Design of micro-strip patch antenna using embedded arrays can be done in future. 


\section{References}

[1] Amit Kumar, UtkarshBesaria and Rjeev Gupta, 'Four-Element Triangular Wideband Dielectric Resonator Antenna excited by a Coaxial Probe', IOSR Journal of Electronics and. Volume 6, Issue 4, pp. 1-6, May. - Jun. 2013.

[2] Yong Mei Pan, Shao Yong Zheng, BinJie Hu, 'Design of Dual-Band Omnidirectional Cylindrical Dielectric Resonator Antenna', IEEE antennae and wireless propagation letters, vol. 13, pp. 710-713, 2014.

[3] Xiaosheng Fang, Kwok Wa Leung, Eng Hock Lim, 'Singly-Fed Dual-Band Circularly Polarized Dielectric Resonator Antenna', IEEE antennae and wireless propagation letters, vol. 13, pp. 995- 998, 2014.

[4] FizzaKhatoon, Amit Kumar, Nidhi Vats, 'Stack of Four Element Triangular Dielectric Resonator Antenna Excited by Coaxial Probe', Volume 4, Issue 5, pp. 287-290, May 2014.

[5] Nidhi, Amit Kumar, FizzaKhatoon, 'Stacked Equilateral Triangular Dielectric Resonator Antenna Excited With Coaxial Feeding', Volume 9, Issue 3, Ver. VI, pp. 1-7, May - Jun. 2014.

[6] Yong-Mei Pan, Kwok Wa Leung, KaiLu, 'Compact Quasi-Isotropic Dielectric Resonator Antenna With Small Ground Plane', IEEE transactions on antennae and propagation, vol. 62, no. 2, pp. 577-585, February 2014.

[7] A.H. Majeed, A. S. Abdullah, F. Elmegri, K. H. Sayidmarie, R. A. Abd-Alhameed, and J. M. Noras, 'Aperture-Coupled Asymmetric Dielectric Resonators Antenna for Wideband Applications', IEEE antennae and wireless propagation letters, vol. 13, pp. 927-930, 2014.

[8] Meng Zhang, Bin Li, XinLv, 'Cross-Slot-Coupled Wide Dual-Band Circularly Polarized Rectangular Dielectric Resonator Antenna', IEEE antennae and wireless propagation letters, vol. 13, pp. 532-535, 2014.

[9] Ranjana Singh, Amit Kumar, 'Multi-segment cylindrical dielectric resonator antenna', Volume 5, Issue 5, pp. 27-35, May 2014.

[10] Vinay Kumar Prajapati, Amit Kumar, Anamika, 'An Array of Four Cylindrical Dielectric Resonator Antenna for Wideband Monopole Like Radiation', International Journal of Engineering Research \& Technology (IJERT), Vol. 3 Issue 5, pp. 2092-2096, May 2014

[11] Sheikh DobirHossain, K. M. AbdusSobahan, Md. Khalid Hossain, Md. MasudAhamedAkash, Rebeka Sultana, Md. MasumBillah. A Rectangular Micro-strip Patch Antenna for Wireless Communications Operates in Dual Band. IJWMT.PP.35-44, 2016.05.04.

[12] T.Jayanthy, I.RexilineSheeba.Design and Analysis of Biquad Patch Antenna with Different Hard Substrates for UWB Applications.PP.58-66, IJWMT.2017.03.06.

[13] A. Rashidian, K. Forooraghi and M. T. Aligodarz. Investigations On Two-Segment Dielectric Resonator Antennas. Microwave and Optical TechnicalLetters.Vol. 45. PP. 533-537. June.2005.

[14] P. Rezaei, M. Hakkak, and K. Forooraghi.Design of Wide-Band DielectricResonator Antenna with a TwoSegment Structure.Progress InElectromagnetics Research PIER 66. PP. 111-124. 2006.

[15] Q. Rao, T. A. Denidni and A. R. Sebak.Broadband Compact Stacked T-Shaped DRA with EquilateralTriangle Cross Sections.IEEE Microwave WirelessComp. Letter. Vol. 16.PP. 7-9. January 2006. 


\section{Authors' Profiles}

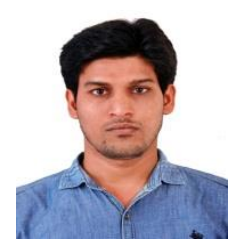

Anant Raj Mishra has done M.Tech and B.Tech in ECE. He has published various research papers in International Journals and presented many research papers in International and National IEEE Conferences. His areas of interest are Communication Systems, Microwave and Antenna \& Wave propagation. He is life member of International Association of Engineers (IAE).

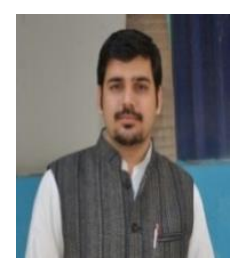

Ankit Gambhir is pursuing Ph.D from Guru Gobind Singh Indraprastha University (GGSIPU) New Delhi. He has done M.Tech (Gold Medalist) in Communication Engineering and B.Tech in Electronics \& Communication. His areas of interest are Communication Systems, Wireless Sensor Network \& Information Security. His 5 research papers are published in International journals of repute. He has presented papers in various International \& National Conferences. He has authored 2 book chapters in Springer.

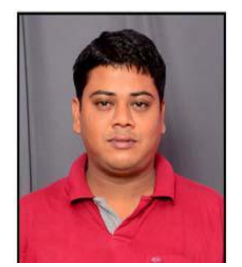

Dr. Rajeev Arya received his PhD in Wireless Communication and Wireless Sensor network from Indian Institute of Technology, Roorkee (IIT-R), India in 2016. He obtained his M. Tech in Communication System from Indian School of Mines Dhanbad (IIT-Dhanbad), India in 2012 and B.E degree in Electrical \& Communication Engineering from Government Engg. College Ujjain (RGPV University, Bhopal), India in 2008. He has received Ministry of Human Resource Development Scholarship (MHRD- India) during M.Tech and Ph.D. His research interests include Wireless Sensor Network, MANET, Ad-hoc Network, Signal Processing, Ant Colony Optimization, Swarm Intelligence, Evolutionary Algorithms, \& soft computing techniques. He has authored book chapters and more than 18 papers in reputed international conferences and journals. He serves as reviewer for IEEE Communication letter, Springer Journal, Thomson Reuter and Scopus indexed journals.

How to cite this paper: Anant Raj Mishra, Ankit Gambhir, Rajeev Arya," Simulation of Rectangular Ring Micro-Strip Patch Antenna to Enhance Impedance Bandwidth for UWB Wireless Applications", International Journal of Wireless and Microwave Technologies(IJWMT), Vol.8, No.1, pp. 34-41, 2018.DOI: 10.5815/ijwmt.2018.01.04 